\title{
Memórias de práticas docentes na EJA: redes outras de formação continuada de professores
}

\author{
Francisco Canindé Silva ${ }^{1}$
}

\section{Resumo}

O trabalho com memórias docentes na Educação de Jovens, Adultos e Idosos (EJA) tem se apresentado como recurso teórico-metodológico outro, capaz de ampliar redes de formação continuada de professores e revelar a diversidade de práticas pedagógicas tecidas no cotidiano escolar. Assim, reconhecer por meio de rastros e reservas da memória, experiências docentes enquanto indícios de formação continuada, se constitui objetivo deste texto, cujo procedimento metodológico - Entrevistas Recursivas - relacionadas a concepções do pensamento complexo, dos estudos do cotidiano e da formação docente para justiça social, propiciaram refletir sobre práticas pedagógicas cotidianas enquanto movimento fértil à autoformação e compreender a rememoração como ato poderoso de formação continuada de professores.

Palavras-chave: EJA; Formação Continuada; Memória; Práticas Docentes.

\section{Memories of teaching practices in EJA: other networks for continuing teacher training}

\begin{abstract}
The work with teaching memories in adults and elderly education (EJA) has been presented as another theoreticalmethodological resource, capable of expanding networks of continuing teacher training and revealing the diversity of pedagogical practices woven in school routine. Thus, recognizing, through memory traces and reserves, teaching experiences as evidence of continuing training, is the objective of this text, whose methodological procedure Recursive Interviews - related to concepts of complex thinking, everyday studies and teacher education for social justice, made it possible to reflect on everyday pedagogical practices as a fertile movement for self-education and to understand remembrance as a powerful act of continuing teacher training.

Keywords: EJA; Continuing Training; Memory; Teaching Practices.
\end{abstract}

\section{Considerações iniciais ${ }^{2}$}

Em tempos de intensas prescrições de como deve ser o trabalho docente, sua formação inicial, continuada, e de como sua prática deve ser aquilatada, faz-se necessário recorrer e priorizar a voz destes profissionais, decorrentes de suas múltiplas experiências pedagógicas cotidianas, para Ihes fazer justiça cognitiva docente (OLIVEIRA; SUSSEKIND, 2016). Desta maneira, reconhecer por meio de rastros e reservas (RICOUER, 2007) da memória, experiências docentes enquanto indícios de formação continuada, se constitui objetivo central deste texto,

\footnotetext{
${ }^{1}$ Universidade do Estado do Rio Grande do Norte (UERN), Campus Avançado da cidade de Assú, canindesilva@uern.br

${ }^{2}$ Este trabalho é parte da pesquisa realizada no período de doutoramento, e atualmente compõe o corpo do texto da tese.
}

Periódico Horizontes - USF - Itatiba, SP - Brasil - e020062 
cujo procedimento teórico-metodológico se organiza em torno de concepções democratizantes e emancipatórias de educação (SANTOS, 2002, 2009, 2010; OLIVEIRA, 2008; MORIN, 2011 CERTEAU, 2011).

A pergunta problematizadora que vem impulsionando a produção dessa reflexão nos contextos da Educação de jovens, adultos e idosos tem sido a de compreender "como memórias de práticas docentes na EJA contribuem, quando desinvisibilizadas e potencializadas para/com processos de formação continuada de professores?" Uma das maneiras que se tem encontrado, é reconhecer estas práticas, é realizar o mergulho profundo com todos os sentidos (ALVES, 2008) nas narrativas do trabalho docente - conversando com esses praticantes, ouvindo-os e fazendoos, pelo exercício da rememoração, perceber-destacar (FREIRE, 2002) práticas emancipatórias possíveis de ressignificação em contextos de formação continuada.

As resistências, táticas operacionais (CERTEAU, 2011), façanhas honestas e eticamente comprometidas com a educação de jovens, adultos e idosos, praticadas-pensadas nos cotidianos desta modalidade educativa e de ensino, no período de 2000 a 2010, foram capturadas por meio de entrevistas recursivas - procedimento metodológico utilizado para conversar com estes profissionais e que nos possibilitou reconhecer inéditos-viáveis (FREIRE, 2002) propícios à formação continuada de professores da EJA.

A escolha pelo período e por memórias recentes (2000 a 2010) deu-se em função de algumas questões consideradas pertinentes de serem explicitadas neste trabalho: (i) o período delimitado é, no contexto do município em que se desenvolve a pesquisa, fértil de abertura de salas de EJA; (ii) a maioria dos professores entrevistados estiveram mais de 05 anos na EJA no referido período; (iii) os rastros da memória recente são mais facilmente lembrados e enlaçados a questões atuais; (iv) a implicação do pesquisador com processos da prática pedagógica enquanto profissional e; $(v)$ o desenvolvimento de pesquisa em nível de especialização na EJA.

O trabalho com memórias docentes na Educação de Jovens, Adultos e Idosos (EJA) tem se apresentado como recurso teórico-metodológico outro ${ }^{3}$ (MACEDO, 2009) capaz de ampliar redes de formação continuada de professores e revelar a diversidade de práticas pedagógicas tecidas no cotidiano escolar. As experiências vividas, trançadas e criadas nos cotidianos por

\footnotetext{
${ }^{3}$ Essa expressão, grafada especificamente por Macedo (2009), refere-se à compreensão metodológica de que rigor e flexibilidade andam juntas na pesquisa qualitativa e autorizam procedimentos criados, para além dos já instituídos.
}

Periódico Horizontes - USF - Itatiba, SP - Brasil - e020062 
professores desta modalidade educativa e de ensino são ricas de conhecimentos outro, invisibilizados na maioria das vezes por lógicas prescritivas e hegemônicas de controle externo.

O texto, portanto, é um convite para um reflexionar acerca de memórias docentes na EJA, pois vivenciando aqueles espaços-tempos estão aptos para contar suas histórias de professores, pois cada um deles transforma-se em um narrador incansável, irrefreável e desejoso de dilatar o tempo para poder dizer sempre e mais sobre o que vivenciou e conteve em si como aprendizado singular na modalidade de ensino.

\section{O trabalho teórico-metodológico com memórias docentes na EJA}

A memória de práticas docentes, apresentada para discussão nesse trajeto de pesquisa, refere-se, como citado, ao período de 2000 a 2010 - constituindo, portanto, uma história do tempo presente. Essa opção justifica-se pelo fato de que a história também se consolida pelo esquecimento (RICOEUR, 2007) e, por isso, deve-se estimular a manutenção da memória do que está sendo produzido no presente, seja em larga ou pequena escala.

Ricoeur (2007), ao apresentar a noção de esquecimento como base para processos rememorativos, parte do pressuposto de que não existe uma memória geral e que, esta, é derivada do esquecimento, campo potencialmente amplo a ser lembrado na atividade de rememoração.

O esquecimento, para o referido autor, caracteriza-se por meio de duas grandes figuras: rastros e reservas. Os rastros são situações, fatos, lugares que marcaram o sujeito em sua experiência cotidiana, cultural e social. Como a memória não tem consciência de tudo que foi esquecido, quem rememora busca, nesses indícios, sustentação para sua retórica. Tais processos de rememoração podem ser realizados por meio de técnicas mnemônicas e, também, por atividades primárias, como a apresentação de imagens, fotografias, palavras chave, utensílios etc.

Ao rememorar, portanto, os praticantes-pensantes da pesquisa buscam no esquecimento as reservas existentes e as manifestam como meio de fazer presente as ausências, atribuindoIhes significados temporais. Assim, pode-se dizer que reservas são matéria do esquecimento; rastros são resíduos da memória que servem aos propósitos da busca, mas que não contêm em si as lembranças. 
O esquecimento convida a uma releitura das duas problemáticas e de sua articulação graças a um princípio novo de discriminação, o dos níveis de profundidade e de manifestação. De fato, o esquecimento propõe uma nova significação dada à ideia de profundidade que a fenomenologia da memória tende a identificar com a distância, com o afastamento, segundo uma fórmula horizontal da profundidade (RICOEUR, 2007, p.424).

A memória é entendida, portanto, como sistema de lutas, de buscas permanentes de reservas do esquecimento, por meio de rastros, com os quais pesquisador e colaboradores podem desenvolver relações e compreensões.

No jogo de memória, de história e esquecimento propostos por Ricoeur (2007), o trabalho com memórias e esquecimento sustenta as lutas e fortalece os grupos sociais que têm suas experiências excluídas pelo pragmatismo da memória arquivista, muitas vezes cronológica e simplesmente resgatada. Neste sentido, as apostas feitas no percurso de pesquisa forjaram-se sobre a memória da história do tempo presente, para que em momentos futuros da história não se tenha apenas uma memória arquivista.

Vista como objeto, a história do imediato é testemunho. Este é seu valor intrínseco. Esse testemunho pode tomar a forma de uma análise que, hierarquizando uma primeira vez as questões, os fatos, fornece conjuntamente arquivos, depoimentos, pistas de pesquisa e esboços de interpretação. (CHAVEAU, 1999, p.24).

Compreende-se com a autora que, certamente, aquele que rememora, escreve história do tempo presente, é testemunha e historiador, apresenta como os demais cientistas, posições ideológicas, morais, éticas, filosóficas e imprime em seu texto oral e/ou escrito esperanças e inquietações de seu tempo. Dessa forma, amplia o retrospecto e o prospecto da história, incluindo ações, rastros e reservas da memória individual e coletiva de sujeitos, e não apenas de alguns poucos como tem feito a historiografia, na maioria das vezes.

Assim, compreende-se também com Guedes-Pinto (2008, p.18) que “a memória, [...] é entendida como uma prática de alteração, como a capacidade de resistir às situações postas, e de crer nas possibilidades". É, portanto, um movimento de recursividade desenvolvido pelos entrevistados e entrevistadores, pois ao rememorar se implicam, reconstroem-se, reconfiguramse e validam suas ações do passado com a reflexão do presente, ao mesmo tempo em que 
projetam perspectivas aos seus sistemas de interesses.

A ideia tem sido a de que o processo de rememorar, lembrar, recordar (RICOEUR, 2007) pudesse dar visibilidade às experiências vividas nas práticas pedagógicas docentes cotidianas, tanto as vivenciadas como as desejadas pelos envolvidos, já que o processo constituiria, segundo o estudioso, um momento de tornar presentes as ausências e de interpretar experiências e vivências humanas de modo a constituir identidades.

A memória também é entendida como a capacidade de enfrentamento dos "problemas do tempo e da história" (LE GOFF, 1990, p.12) e representa possibilidades de luta, de emancipação de grupos em relação a outros de natureza autoritária. Mas, deve representar, principalmente, oposição a modelos reducionistas de produção do conhecimento, em que as vozes dos praticantes-pensantes cotidianos são frequentemente silenciadas.

O trabalho com a memória, e especialmente com a memória coletiva, tem permitido visibilizar e conservar determinadas informações do passado que não são consideradas no fazer tradicional da história, favorecendo a articulação de projetos de intervenção sobre realidades sociais, e, entre tantas outras funcionalidades, colaborando com a construção identitária de grupos historicamente excluídos por modelos de organização social hegemônico.

A memória coletiva é não somente uma conquista, é também um instrumento e objeto de poder. São as sociedades, cuja memória social é sobretudo oral, ou que estão em vias de constituir uma memória coletiva escrita que melhor permitem compreender esta luta pela dominação da recordação ou da tradição, esta manifestação da memória (LE GOFF, 1990, p.476).

Nesse marco, Halbwachs (2006) entende que a memória coexiste com os testemunhos, que são interpretações individuais resultantes de um processo social mais amplo, e que quando evocados pelas lembranças podem produzir o que denomina de memória coletiva. Desse modo, compreende-se que o trabalho com a memória significa ruptura com modelos clássicos da historiografia, em que o social é definido por meio de metanarrativas, e em que o individual (o minúsculo, o residual, o trivial) é excluído desse processo.

As memórias individuais são reconstruções de acontecimentos, eventos e poucas vezes a sua simples decodificação. Nesta mesma direção, Le Goff $(1990$, p.9) afirma que "o processo de memória no homem faz intervir não só a ordenação dos percursos, mas também o modo de os 
interpretar".

Entende-se, então, que as memórias específicas das práticas docentes dos profissionais da educação de jovens e adultos, sejam elas orais ou escritas, representam identidades culturais em específicos contextos históricos, políticos e sociais em que os praticantes-pensantes se inserem como autores e/ou coautores de um processo mais amplo, mas que se diferencia pelo modo particular como percebem, pensam, entendem e produzem esses espaços-tempos das práticas docentes.

Do ponto de vista da metodologia de estudo, o trabalho com memórias pode até parecer muito simples, mas não se trata apenas de uma técnica de pesquisa, e sim de uma abordagem teórico-metodológica que exige esforço argumentativo, interesses democratizantes e concepções político-epistemológicas dos envolvidos. É preciso mergulhar com os rememoradores no tempo da ação rememorada e sentir com eles os processos de reconhecimento, acompanhar cada gesto, cada silêncio, alegrar-se ou silenciar quando a memória oscilar.

Realizar um trabalho de pesquisa recursivo, em que os profissionais entrevistados se reconhecem, por meio de suas memórias, como produtores autônomos de saberes, desafia a lógica da objetividade, do determinismo, da estabilidade, das certezas que vêm ranqueando os saberes e conhecimentos em maiores e menores.

A esse respeito, enfatizo que o aprendizado e os movimentos de rememoração são fundamentais na formação dos sujeitos, na construção e compreensão de suas histórias de vida pessoal e profissional. Essa compreensão conduz o sujeito à criação de sua própria história e garante-Ihe autonomia enquanto sujeito social.

Reconhecendo-se potencialmente capaz de produzir sua história, rememorando suas práticas docentes, os profissionais da educação e da educação de jovens e adultos colaboram para que outros homens e mulheres - seus alunos - sem alfabetização e/ou pouca escolarização, reencontrem-se e deem sentido ao processo educativo tão necessário na atualidade como integrante do marco de aprender por toda a vida.

As memórias específicas das práticas pedagógicas cotidianas destes profissionais são entendidas, neste percurso, e de acordo com Le Goff (1990, p.11), como "[...] a base, qualquer que ela seja, sobre a qual se inscrevem as concatenações de actos". Por isso mesmo, as apostas 
e compreensões tecidas pelo processo de rememoração se deram no marco das memórias sociais, reveladoras de modos de enfrentamento dos problemas do tempo e da história e, mais que isso, revelaram-se instrumento de poder. Por isso, recorro aos contextos em que essas práticas pedagógicas docentes foram desenvolvidas e nos quais a memória foi tecida.

Assim, com base nos pressupostos de memória individual e coletiva, de memória esquecimento, de memória histórica, de memória, e de memória da história do tempo presente traduzo lembranças de professores locais sobre práticas docentes cotidianas da educação de jovens e adultos, enlaçando-as como indícios de formação continuada.

\section{A questão da experiência docente na EJA no contexto da memória recursiva}

Tomar as práticas docentes rememoradas por meio de entrevistas recursivas, enquanto campo singular de estudo, implicou reconhecer entre os diversos elementos e dispositivos que as constituem, a força da experiência, entendida, nesse caso, como aprendizado construído paulatinamente pelos sujeitos envolvidos.

A cultura científica moderna, em muitas de suas assertivas, rejeitou e/ou excluiu dos processos de análise as práticas como objeto de estudo, afirmando não existir ciência na prática e, talvez, por isso mesmo, a experiência enquanto campo fértil de estudos tenha sido subjugada ao plano do senso comum que, segundo a abordagem científica moderna, não é verificável e passível de generalização.

A orientação adotada ao estudar práticas docentes na EJA, tendo como ponto de partida suas experiências, deu-se a partir de alguns movimentos, pelos quais a pesquisa se organizou.

O primeiro refere-se à luta contra-hegemônica que vem sendo feita em relação aos modelos de ciência cartesiana e iluminista, e se caracteriza de acordo com Santos e Meneses (2010, p. 54) como uma ecologia de saberes, pois "tem como premissa a ideia da diversidade epistemológica do mundo". O mundo é, segundo esse mesmo pensador, bem mais amplo de noções, pontos de vista, do que comporta a forma abissal da ciência tradicional. A ecologia de saberes acredita na existência de outros saberes não científicos, e pensa que esses saberes são potencialmente úteis aos seus praticantes, de modo que a ordem, o determinismo, a prescritividade e a disciplinarização da ciência reducionista perdem sua força colonizadora e 
imperialista.

Na discussão sociológica de Santos (2002) acerca das não existências como produção social, como partes desqualificadas da totalidade homogênea, é proposto o questionamento sobre cada uma dessas lógicas, ao mesmo tempo em que é revelada a multiplicidade e a diversidade de práticas sociais, bem com sua credibilidade. Esse movimento de irrupção e recursividade é, para o referido autor, a superação das lógicas monoculturais e adoção de uma lógica da multiplicidade e da diversidade, denominada conceitualmente ecologia, como anteriormente mencionado.

Nesse sentido, experiências de práticas pedagógicas docentes da EJA estão sendo compreendidas como relações interdependentes de saberes, significando tudo aquilo de que praticantes fazem uso, decorrente de aprendizagens produzidas à margem do saber formal. As referidas aprendizagens foram, por muito tempo desperdiçadas, visto que não se enquadravam no rigor do conhecimento científico moderno (na escola, representado pelo currículo oficial), mas sobreviveram marginalmente à sua maneira - fugidias, exóticas, estranhas etc.

Mas, por que foram invisibilizadas, não consideradas nas possíveis relações interativas de planejamento e nos processos sistemáticos de formação continuada? Quem invisibiliza esses saberes que produzem experiências? Que conhecimento tem autorizado a negação dessas práticas comuns? E, simultaneamente à negação - quem alternativamente as vem produzindo? Como são produzidas?

Para responder a essas questões e poder melhor explicitar o que representam as experiências nessa construção epistemológica complexa, Santos (2009) define duas concepções de conhecimento que têm matizado o modelo de racionalidade moderna: o conhecimentoregulação e o conhecimento-emancipação, ambos tecidos na perspectiva deste paradigma dominante, mas com objetivos, princípios e perspectivas diferenciadas, implicadas e interdependentes, mesmo que algumas não reconhecidas. Pode-se afirmar que o conhecimentoregulação surge das relações hegemônicas do paradigma hegemônico da modernidade, se legitima por seus ideais e valores; já o conhecimento-emancipação, embora seja uma criação indesejada pelo paradigma dominante, sobrevive a ele e constitui aposta de um paradigma emergente.

Santos (2009) afirma ser todo conhecimento uma progressão entre um ponto ou estado 
A denominado ignorância, para um ponto ou estado $B$, denominado saber e se distinguem esses pontos pelos modos como se caracterizam cada um deles ou as trajetórias que conduzem de um ao outro. Sob esse aspecto, reforça a ideia de não existir saber mais e saber menos, pois tanto a ignorância como o saber têm um conjunto de experiências próprias de suas trajetórias. "Todo o saber é saber sobre uma certa ignorância e, vice-versa, toda a ignorância é ignorância de um certo saber" (SANTOS, 2009, p.78). Assim, explicita a partir do paradigma da modernidade que existem duas formas principais de conhecimento: o conhecimento-emancipação e o conhecimento regulação.

O conhecimento-emancipação é uma trajectória entre um estado de ignorância que designo por colonialismo e um estado de saber que designo por solidariedade. O conhecimento-regulação é uma trajectória entre um estado de ignorância que designo por caos e um estado de saber que designo por ordem (SANTOS, 2009, p.78).

Visto por esse ângulo, parece simples a ideia de como se organizam as duas formas principais de conhecimento moderno, mas é preciso mergulhar mais intensamente em Santos (2009) e perceber que o conhecimento-regulação edificado pela trajetória que vai do caos à ordem tem prevalecido e marginalizado saberes praticados-pensados solidariamente como conhecimento-emancipação. Segundo o referido autor, o conhecimento-regulação, valendo-se de uma das três lógicas de racionalidade - a cognitivo-instrumental, que tem a ciência e a tecnologia como matriz de sistematização, se foi impondo de tal modo, que a ordem (saber disciplinar, cientificista, instrumental) se transformou na forma hegemônica de saber, e o caos (saber periférico, à deriva, inusitado) transformou-se no modo hegemônico de ignorância.

Experiências de práticas pedagógicas docentes, compreendidas por essas perspectivas de conhecimento, especificamente pelo conhecimento-emancipação, têm se apresentado aos pesquisadores cotidianistas como saber solidário, caótico e não dito, opondo-se a formas mecânicas de análise a que são submetidas as práticas. A tentativa tem sido, sempre, a de reinventar e revalorizar saberes clandestinamente produzidos pelos praticantes-pensantes cotidianos. Contudo, a tarefa da reinvenção e revalorização de experiências das práticas pedagógicas cotidianas supõe, parafraseando Santos (2009), um trabalho de imaginação sociológica/pedagógica a fim de, por um lado, visibilizar práticas que foram invisibilizadas e, por 
outro, traduzir pelos indícios, potencialidades em possibilidades.

Em consonância com essas proposições reflexivas, acredito que a rememoração das experiências de práticas pedagógicas docentes vividas diretamente pelos professores da educação de jovens e adultos no período delimitado por essa pesquisa significou, entre outras possibilidades, tirá-las do silenciamento; fazer emergir o que era até então anonimato didático, potencializando indícios e sinais reconhecidamente possíveis de ampliação e transformação.

Assim, percebe-se que as rememorações feitas pelos professores de EJA, referentes às suas práticas pedagógicas docentes, traduziram com maior qualidade seus anseios, capacidades, qualidades, necessidades e expectativas formativas. As experiências representaram contextos intrapessoais e interpessoais dos professores, e porque não dizer da docência, enquanto atividade profissional na EJA como modalidade de ensino, e da própria referência de educação que se tem deste período.

\section{Sobre as entrevistas recursivas}

Na continuidade da conversa, explicita-se o que se está compreendendo por entrevista recursiva, a fim de facilitar a compreensão e as articulações teórico-epistemológicas empreendidas por esta escolha e definição. É uma entrevista dialógica em que os sujeitos envolvidos recorrem a todo momento, com liberdade, por meio da memória, a experiências vivenciadas em seus múltiplos cotidianos sociais, culturais e educativos, valendo-se especificamente de rastros e reservas para articular compreensões no presente.

Para as finalidades a que se propõe este trabalho - reconhecer práticas pedagógicas docentes existentes e possíveis nos cotidianos escolares da Educação de Jovens e Adultos propositivas a formação continuada de professores-, as entrevistas recursivas se compõem de características das entrevistas semiestruturadas, seguidas de uma conversa sobre as questões desenvolvidas, podendo alterar esse status sempre que um dos envolvidos perceber não correspondência com o proposto como temática da entrevista.

Nesta pesquisa, a opção pelo uso de entrevistas enquanto recurso metodológico esteve atrelada às seguintes questões: primeiro, ao trabalho de rememoração realizado junto aos profissionais da Educação de Jovens e Adultos; segundo, pelas apostas feitas no paradigma da 
complexidade, enquanto sustentáculo teórico da pesquisa; e terceiro, pelo caráter recursivo que se implementou ao longo de todo o trabalho de investigação.

A partir dessas perspectivas chegou-se à compreensão de que entrevistas têm formatação metodológica coerente com os pressupostos teóricos assumidos, mas, para que a qualidade proposta nos objetivos pudesse, de fato, ser alcançada, acoplou-se a esse procedimento um dispositivo do pensamento complexo - a recursividade.

Recursividade (do latim recurrere - tornar a correr, percorrer de novo) significa, de acordo com Morin (2011, p.87), que "os efeitos e produtos são necessários para o processo que os gera. O produto é produtor do que o produz". Enquanto princípio da complexidade, a recursividade rompe com a ideia de separação entre produto/produtor, causa/efeito e passa a perceber esses elementos e situações em espiral, ou seja, auto-organizando e autoproduzindo-se.

Pode-se afirmar, a partir desse conceito de Morin (2011), que a recursividade é uma causalidade complexa, porque reúne, reorganiza e coloca em interação o antagônico, o paradoxal e o contraditório, confrontando, superando, sem negar as individualidades e/ou até mesmo reduzi-las. Seu objetivo é imobilizar e inibir a racionalidade linear, por entender que o produto produz o produtor que, por sua vez, produz o produto e, assim, como no redemoinho, a complexidade vai sendo tecida:

A ideia recursiva é, pois, uma ideia em ruptura com a ideia linear de causa/efeito, de produto/produtor, de estrutura/superestrutura, já que tudo que é produzido volta-se sobre o que produz num ciclo ele mesmo autoconstitutivo, auto-organizador e autoprodutor (MORIN, 2011, p.74).

A denominação de entrevistas recursivas é, nesse entendimento e, consoante com o paradigma da complexidade, uma aposta, no sentido de que todas as coisas são, ao mesmo tempo, causa, causante e consequência, sistemas que se auto-organizam em função dos modos como se percebem e tecem a realidade. As entrevistas, portanto, se efetivaram para o entrevistador e entrevistados de modo recursivo, visto que a rememoração exigiu reiteradas compreensões sobre os sistemas de interesse, tanto do pesquisador implicado na trajetória da EJA, como dos sujeitos parceiros entrevistados, implicados com a modalidade de ensino.

Neste sentido, as contribuições de Morin (2011) foram fundamentais ao processo de 
elaboração e realização das entrevistas, incluindo de seu pensamento o dispositivo operacional da dialogicidade; o princípio da auto-eco-organização e o princípio hologramático.

O objetivo proposto para as entrevistas recursivas eram as práticas pedagógicas docentes da EJA e, no exercício de rememoração com professores, perceber, a partir das situações expostas, o que se caracterizava como ausente, emergente e passível de tradução, segundo a abordagem sociológica de Santos (2002), ao processo formativo continuado dos referidos docentes.

\section{Memórias de experiência recente: práticas docentes em recursão}

As experiências rememoradas das professoras permitiram, no enlaçamento com o arranjo teórico defendido ao longo do texto, articular complexidades a fim de melhor compreender diferentes práticas pedagógicas e processos de formação continuada de professores, tendo como ponto de mutação ausências e emergências. Destaca-se, para esta reflexão, um 'extrato' de uma das entrevistas realizadas, no formato que originalmente se assumiu.

Praticante-pensante ${ }^{4}$ da pesquisa: Socorro Barbosa - uma professora de Letras há 25 anos na EJA.

Professora, recentemente aposentada (2015), 25 anos de trabalho em sala de aula com educação de jovens e adultos. Graduada em Letras e especialista em Linguística. Atualmente desenvolve, a partir do segundo vínculo empregatício junto à rede estadual de ensino, a função de coordenadora de banca examinadora de exames supletivos.

Socorro Batista, tem uma história com educação de jovens e adultos, produzida pelo inusitamento e pela imprevisibilidade, como ela mesma fala: "Aprendi a dar aula dando aula, ninguém me ensinou na faculdade, nenhum curso me ensinou a dar aula porque o que me ensinou a dar aula foi a minha vivência com o aluno, e isso é gratificante". Sua experiência traduz o modo como os professores, depois de formados, são designados a exercer a docência na modalidade de Educação de Jovens e Adultos - o que pensam, como reagem, que desafios

\footnotetext{
${ }^{4}$ O nome atribuído a praticante-pensante não corresponde ao seu nome de registro civil, opção declarada pela entrevistada em nosso primeiro encontro e assinada em Termo de Consentimento Livre e Esclarecido.
} 
enfrentam ao se perceberem estranhos a esta realidade? A crítica recai, inicialmente, sobre os currículos de formação inicial (graduação/licenciatura) que, em maioria, pouco ou nada discutem sobre a modalidade de ensino da EJA, mas articula, ao mesmo tempo, a possibilidade de que sistemas de ensino pensem sobre o desafio de organizar formação específica para os professores em início de carreira.

É possível perceber, a partir da rememoração que D. Antônia faz de sua prática pedagógica, outras possibilidades de formação que emergem da relação estabelecida com estudantes, com companheiros de trabalho e com as próprias circunstâncias em que o trabalho se efetiva. Ao entrar em contato com estudantes, com o projeto pedagógico da escola e com toda a nova realidade que se apresentava a ela, a professora desenvolveu táticas de operacionalização não previstas, criando simultaneamente modos de sobreviver aos desafios e atender demandas específicas, obtendo sucesso em alguns momentos e em outros não.

\section{Entrevistando a profa. Socorro Barbosa [em 17 jun. 2014] $]^{5}$}

\section{Primeiras palavras}

"Bem professor! Não sei se vou ser útil para o que você está precisando, mas vou tentar chegar lá... comecei trabalhando nessa modalidade de ensino, não por escolha, diria que foi quase por uma circunstância. Passei em um concurso público e a escola que dispunha de vaga era esta que trabalhei ao longo desses anos no noturno, com essa modalidade de ensino. Então, quando fui aprovada, necessariamente - sou franca em lhe dizer - , não sabia de nada [da prática didático-pedagógica] para essa modalidade de ensino. O curso em que me formei não era muito apropriado, porque não se desenvolve [ensina] muita prática pedagógica - Letras. Mas, como sou uma 'fanzoca' da nossa Língua Portuguesa, nela tudo me encanta, então sentia firmeza em minhas aulas, mais pelo que eu sabia que iria fazer, do que mesmo pela prática, certo?"

Entrevistador: E como fez para trabalhar com esse público tão específico?

\footnotetext{
${ }^{5}$ A Entrevista Recursiva apresentada nesse formato - tamanho de fonte, espaçamento e na íntegra, refere-se a uma concepção de entrevista em construção, adotada no doutorado em Educação, refletindo mais amplamente o movimento de compreensão com o entrevistado. Mantemos, entre outras questões, os usos da língua do entrevistado, a fim de traduzir mais amplamente os sentidos atribuídos.
}

Periódico Horizontes - USF - Itatiba, SP - Brasil - e020062 
Profa. Socorro Barbosa: Quando se ensina o que se sabe, e como graças a Deus, eu tinha certa bagagem, sempre me encantei pelo ato de ensinar e, quando a gente se encanta por alguma coisa, se interessa e aprofunda-se naquilo que a gente gosta, e como era muito ligada ao ensino, fui aos poucos elaborando minha prática.

Entrevistador: Como a escola, que já trabalhava com EJA Ihe ajudou nesse sentido?

Profa. Socorro Barbosa: Existia um suporte pedagógico que me ajudava muito, mas tinha que me ajudar mesmo, afinal exigia que trabalhássemos de acordo com o projeto político pedagógico da escola. Como sempre fui uma professora desobediente, fugia um pouco da prática planejada para trabalhar a vivência do aluno.

Entrevistador: Como foram ocorrendo seus primeiros contatos com as turmas de jovens e adultos na escola?

Profa. Socorro Barbosa: A realidade desta modalidade é diferente do ensino regular, a gente trabalha com alunos diferenciados, alunos que vivem uma vida diferente, com famílias desestruturadas, pais separados, alunos drogados, mães solteiras, e a maioria dos estudantes trabalha; os homens trabalham o dia todo, as mulheres desenvolvem funções de domésticas, e uma boa parte dos estudantes são adultos, idosos.

Entrevistador: Como pensou suas aulas, que metodologias desenvolveu face às especificidades das turmas?

Profa. Socorro Barbosa: Percebia que os estudantes não se sentiam à vontade para participarem de atividades, tais como: dinâmicas, jogos, técnicas e outras propostas planejadas com o apoio pedagógico. A gente aplica essa metodologia, mas não vê resultados... eles querem aprender a ler e escrever somente pelo modo mais tradicional. Quantas e quantas vezes cheguei com o plano de aula para repassar, mas quando começava, logo diziam: "- professora, a gente não está entendendo!" Então, largava o que estava fazendo e passava a desenvolver atividades que mais Ihes interessavam. Aliás, nunca nestas turmas dei aula somente pelo livro didático, eu dava aula pelo que eu via, planejava em casa pelo que eu sentia da necessidade dos alunos. Quando chegava e dizia, por exemplo: vou dar uma aula de fonética, o aluno respondia "professora, não sei!" Eu perguntava: "não sabe nem uma sílaba, nem separá-las?" Você acredita, muitos deles não conhecem /K/, /W/, /Y/ que foram incluídos no alfabeto! Então, você já viu! São coisas que a gente tem que replanejar, refazer para que eles possam aprender. Nunca fui 
muito apegada às normas, mas tentava me orientar pelo projeto político pedagógico (PPP) da escola, mas sempre achei difícil.

Entrevistador: O que o replanejar acarretava?

Profa. Socorro Barbosa: O trabalho como professora de Língua Portuguesa permitia que eu fizesse um trabalho diferenciado, respeitando a vontade do aluno. Acredito que nós, professores da EJA, temos que fazer com que o aluno sinta firmeza no que estamos dizendo, se ele sentir que o professor não tem firmeza no seu trabalho, ele também não dará crédito, e se isso não acontece, eles se desinteressam e saem falando da gente [criticando negativamente]. Eles dizem mesmo, por exemplo, quando o aluno não está interessado em assistir uma determinada aula e sente que o professor tem firmeza, tem conteúdo, mesmo saindo de sala, demonstram respeito e confiança. Mas, quando percebem que um professor não tem firmeza, dizem simplesmente: "- não vou assistir essa aula, não estou com vontade, porque esse professor não sabe de nada, está só conversando, contando casos e isso não me interessa."

Entrevistador: Como você foi estabelecendo essa relação de confiança com os estudantes em sala de aula e na escola?

Profa. Socorro Barbosa: Compreendo que nós, professores, temos que envolver o aluno e fazer com que ele sinta firmeza, tenha confiança na gente; temos que respeitá-los como são sua diversidade, contexto social, como ele é, como chega até a escola; temos que respeitar e fazer com que nos respeite. Precisamos perceber que o aluno está em sala de aula com um objetivo, e muitas vezes chegam à escola e à sala de aula com necessidades urgentes, querendo resolvê-las imediatamente. Geralmente, dizem: "- eu quero terminar meu curso, para poder melhorar no meu trabalho." E pergunto: "- como você quer melhorar em seu trabalho, se você não acompanha os conteúdos de sala de aula?" Nesse caso, a gente sente também o estado de espírito do aluno. O professor que trabalha com a EJA tem que ter um lado psicológico [risos], tem que ser completo, além do conteúdo deve ter um lado psicológico, motivacional para que também entenda melhor o referido aluno. Ano passado, um senhor, já bem idoso, assistia aula comigo, pedi para que lesse um pequeno texto, mas percebia sua inibição. Ficava com pena de pedir para ele ler. Ficavam pálidos, agressivos, desnorteados e caçoavam deles mesmos.

Entrevistador: Esse estudante que a senhora pediu para que fizesse a leitura estava em qual ano/série? 
Profa. Socorro Barbosa: Era do sexto e sétimo ano, aqui funciona semestralmente. Eu senti que o aluno ficou um pouco agressivo e até procurou uma intriga afirmando que eu estava discriminando-o, porque havia pedido para ler. O aluno me falou: "- por que me pediu para ler, se eu não sabia? Tinha tantos outros na sala, por que me escolheu?" Respondi-lhe: "- eu não escolhi, apenas pensei que você já soubesse ler."

Entrevistador: $\mathrm{O}$ que foi feito com o estudante, mediante tal problemática?

Profa. Socorro Barbosa: Então, pensei! Vou trabalhar melhor esse aluno; tenho que trabalhar o aluno; a gente às vezes chega à sala, com aula bem planejada, tudo bem bonitinho e dá aquela aula expositiva (que é o que eles querem, se não tiver, eles dizem que o professor tá enrolando na sala de aula). Então, quando a gente termina de explicar, percebe aquele olhar vazio do aluno. Não entenderam nada, porque o nível está bem abaixo do que eles ouviram.

Entrevistador: Poderia falar melhor de como é esse processo da explicação e de como o não entendimento aconteceu, Profa. Antônia?

Profa. Socorro Barbosa: Vou começar com um exemplo. Encontro vocálico, para eles é uma coisa utópica, porque ainda não sabem nem o alfabeto direito (codificar/decodificar). Explico diversas vezes, mas não conseguem entender. Aluno da EJA é muito atrasado! Digo sempre lá na escola, agora não mais, porque saí de sala de aula, mas digo sempre: "- gente, eu acho que o processo de alfabetização na Educação de Jovens e Adultos era para ser mais rigoroso, uma coisa melhor trabalhada, para não se mandar um aluno para o sexto e sétimo ano sem saber ler e escrever corretamente." O professor no 6ㅇ e 70 ano vai trabalhar os conteúdos programados e termina por desviar todo o planejamento que fez, ao perceber que os alunos não acompanham. Sou sincera em dizer: deixei de planejar pelo livro; faço minha aula de acordo com o que eu estou sentindo e vendo como necessidade dos alunos. Quando dou aquela aula, que eles gostam muito, entendem, especialmente da parte ortográfica, dizem: "- professora, adorei sua aula hoje, entendi tudo, eu não sabia que pássaro se escrevia com dois /ss/." Dizem também: "- eu não sabia que nascer não se pode dizer na/s/cer." Então, a gente tem que envolver pronúncias; o ensino da língua portuguesa em si é complexo e para as pessoas que passam o dia todinho sem poder pegar num livro para estudar, só vêm à noite, e muitas vezes cansadas, então ele tem que ser trabalhado, bem trabalhado, sem pressa de terminar aquele conteúdo.

Entrevistador: E o que fazia com esses acontecimentos, afastando-a de seu 
planejamento?

Profa. Socorro Barbosa: Nunca terminei o conteúdo planejado para o ano letivo. Os alunos não entendem o que é regência verbal; o que são figuras de linguagem; têm muitas dificuldades para acompanhar as questões que envolvem cada um dos conteúdos. Fico sempre me questionando como conseguiram chegar até ao sexto e sétimo ano. Como não consigo passar adiante, volto para questões mais elementares da alfabetização inicial para que possam se sentir mais envolvidos. Confesso que, ao longo desses anos, foi difícil saber o que de fato ensinar aos alunos jovens e adultos. Agora, respondendo a sua pergunta, falo sempre para eles: "- vocês têm livros didáticos (eles têm livro didático), leiam quando estiverem em casa; peçam a alguém para ajudá-los; dirijam-se até a biblioteca, busquem outros livros; quando tiverem dúvidas me perguntem; façam de tudo para aprender. Vocês são capazes, têm muita experiência e isso pode ajudar." Vou a cada dia tentando fazer coisas diferentes, observando sempre aquilo que eles têm mais necessidade. Fica até difícil de relatar tudo o que já passei e inventei para que os alunos aprendessem o mínimo da língua portuguesa. Confesso que o planejamento feito a partir dos livros didáticos não deu muito certo; não sei se com os meus colegas tem acontecido o mesmo, ou se é diferente. A verdade é que não dava para seguir o conteúdo dos livros com o nível de alfabetização dos alunos.

Entrevistador: Como era então, a relação de aprendizagem com esses estudantes?

Profa. Socorro Barbosa: O aluno da EJA é um aluno bom de trabalhar, só tem essa fragilidade de aprendizagem [de alfabetização, assinalo eu], mas é um aluno que tem experiência de mundo; é uma experiência extracurricular que se dá no próprio caminhar do aluno, em seu meio cultural, social e religioso. Aquele conteúdo de mundo, que é muito importante, a gente tem que vivenciar e valorizar, aprender muito com isso, afinal, são conhecimentos diferentes dos nossos, temos que respeitar.

Entrevistador: No período em que lecionou nesta escola participou de algum curso de formação (atualização, aperfeiçoamento, capacitação)?

Profa. Socorro Barbosa: Não! Para isso não! Participava de outras formações (na área de língua portuguesa), porque sempre fui uma pessoa lutadora, muito danada, no sentido vulgar da palavra, para buscar conhecimento. Meu aprendizado foi com o próprio aluno, sua realidade. Minha prática pedagógica foi moldada, estabelecida e aprimorada pela experiência e, também, 
pelo projeto pedagógico da escola; apoiava-me em alguns colegas de trabalho, suas experiências didáticas e também compartilhava as dificuldades.

Entrevistador: E os planejamentos como aconteciam?

Profa. Socorro Barbosa: Infelizmente, não aconteciam! Somente na semana pedagógica da escola, no início do ano letivo é que fazíamos muito rapidamente uma relação do que seria ensinado, a partir do livro didático a ser utilizado pelo professor e alunos. A supervisão escolar para este turno quase nunca existiu e isso fazia com que o planejamento coletivo na escola não acontecesse. Sentia muita falta de uma supervisão para nos orientar e nos ajudar, especialmente quando comecei e não tinha nenhuma experiência didática, o curso de Letras não me preparou para dar aulas. Ficava sempre muito aflita com a evasão e não tinha uma supervisão/coordenação pedagógica para recorrer. Às vezes recorria à supervisão de outro turno da escola, mas o negócio não funcionava bem.

Entrevistador: E a evasão era um problema? Pode me falar um pouco sobre isso?

Profa. Socorro Barbosa: Sim! A gente começava o ano letivo com as salas sempre cheias, mas depois do primeiro semestre a evasão era grande. Após o período junino, festa maior da cidade, os alunos não voltavam mais, pelo menos boa parte deles.

Entrevistador: O que você fazia diante de tal situação?

Profa. Socorro Barbosa: A gente não tinha um trabalho muito diferenciado, sempre se repetia por conta da falta de apoio pedagógico no ambiente de trabalho. Nós mesmos, professores, é que procurávamos inovar, fazer uma coisa diferente, porque a gente sabe que a condição social da escola não é só transferir conhecimento e formar cidadãos para o exercício de sua cidadania oficial, mas também é fortalecer seus valores. A gente sabe que, embora eles não entendam isso, nosso trabalho é prepará-los para a vida. A gente tem que fazê-los cidadãos do mundo. Sobre a evasão, procurávamos saber por que eles se evadiam/desistiam. Alguns dizem que vêm à escola por ser o único lugar da noite para ficar fora do nosso ambiente familiar (os mais jovens) e isso me entristece; outros vêm à escola como uma atividade de rotina - talvez sintam necessidades de uma aula mais articulada, mais chamativa. Mas, a maioria mesmo não quer nada. Tem alunos que desistem já no final do ano letivo, eles dizem: "- eu não aguento mais, estou vindo de longe, os ônibus faltam; não aguento mais, chego do trabalho na hora de vir pra aula, quando chego em casa não aguento mais de tanto cansaço." Outros dizem: "- não 
tenho companhia para vir, moro aqui na cidade, em bairro que não me dá condição de vir sozinha (as meninas dizem isso)".

Entrevistador: Ao longo desses 25 anos em que você trabalhou nesta escola com educação de jovens e adultos, foram pensadas/desenvolvidas algumas coisas que pudessem ajudar a combater a evasão?

Profa. Socorro Barbosa: A escola pensou! Mas, tem alguns professores arcaicos que dificultam o trabalho, achando que a responsabilidade de aprender é unicamente dos alunos. Conversamos individualmente com os alunos; explicamos a importância da escola para suas vidas; elaboramos alguns projetos. Enfim, fizemos com todos os atropelos algumas coisas, infelizmente não foram suficientes para resolver o problema da evasão.

Entrevistador: Particularmente, tem alguma experiência didática que gostaria de ressaltar como positiva nesse trajeto?

Profa. Socorro Barbosa: Lembro-me de algumas com muita clareza e saudade. Hoje, vejo alunos que por mim passaram, trabalhando; fazendo faculdade; outros com ensino médio completo. E tudo isso me deixa, de certo modo, orgulhosa. Lembro particularmente de um trabalho que eles fizeram - um livreto. A turma era de nono ano e a temática do livrinho era sobre "a história de cada um". Tentamos fazer com capa dura, mas infelizmente os recursos não apareceram e finalizamos com encadernação somente. Lembro bem que muitos alunos se empolgaram e produziram histórias bacanas, ficaram entusiasmados com a atividade, trouxeram até fotos, contaram intimidades e muitas outras coisas.

Entrevistador: O que ficou como aprendizado desta experiência com educação de jovens e adultos ao longo destes 25 anos de magistério?

Profa. Socorro Barbosa: Posso lhe afirmar que aprendi muito, mas tem umas coisas que hoje considero importante: penso que o professor não é aquele que vai da faculdade direto para a sala de aula; o professor é aquele que aprende na sala de aula - aprende e ensina, e aprende ensinando. O professor nunca está pronto, mesmo com especialização, mestrado, doutorado, ele nunca está pronto, porque a gente nunca deixa de aprender. Aprendi a dar aula dando aula, ninguém me ensinou na faculdade, nenhum curso me ensinou a dar aula porque o que me ensinou a dar aula foi a minha vivência com o aluno, e isso é gratificante. 


\section{Traduções à formação continuada de professores}

A trajetória da Profa. Socorro Barbosa, por suas práticas pedagógicas cotidianas rememoradas (complexidade) e até mesmo pelas semelhanças com outras histórias docentes da Educação de Jovens e Adultos, não se integra aos requisitos estabelecidos pelo cânone da profissão, e tampouco serve às propostas de formação continuada socialmente institucionalizadas. Seus saberesfazeres na modalidade se tecem a cada dia pelo contato e na interação que mantêm com os estudantes, embora se perceba que há conflitos internos, gerados pela vontade de efetivar um conjunto de saberes disciplinares produzidos durante a formação inicial, sobre o que se deve ensinar em Língua Portuguesa, independente do fato de os sujeitos serem falantes competentes da língua oral.

As experiências pedagógicas, cotidianamente criadas no percurso da profissão, revelamse potencialmente enredadas aos desafios postos pelos contextos de direito, social (éticopolítico) e pedagógico, em que a modalidade de ensino foi se efetivando, incluindo aqueles que constituem o que denomino a partir de Santos (2002) de ausências e emergências. As práticas pedagógicas de Socorro são, por isso, indícios da luta que milhares de professores da EJA enfrentam diariamente, para manter a qualidade de ensino nas salas de aula, qualidade na profissão e, principalmente, na aprendizagem dos alunos. Assegurar nas práticas o direito de aprender, com ausência equiparada de recursos financeiros, de formação pedagógica adequada, de baixa aceitação/compreensão dos companheiros de profissão, da gestão e até mesmo enfrentando o preconceito da comunidade é, de fato, desafiador para todos aqueles que encaram a docência na EJA com seriedade e compromisso.

As práticas não formais da professora, reconstruídas por suas memórias, assemelhandose a de tantas outras - se tornarão efetivamente viáveis quando expostas ao debate, pelo diálogo, e em recursão permanente com os próprios praticantespensantes, por meio de processos de formação continuada. Socorro, em seu relato, reclama a presença de apoio pedagógico para ajudá-la a pensar a prática, e com isso evidencia a necessidade de formação com características dialógicas, transversais, auto-organizativas - que o pensamento complexo, multirreferenciado defende.

Formação continuada, como sistema complexus, integra, relaciona e autoproduz os 
acontecimentos cotidianos, enredando-os em complexidade abertas e transitivas, designando o professor para um percurso continuado de aventuras com o conhecimento. Assim, o professor atravessa e é atravessado por processos de complexificação histórica, política, social e cultural, que, embora antagônicos, não estão separados em mundos opostos, mas mutuamente hibridizados, desafiando cada um a distingui-los nas práticas pedagógicas cotidianas.

Assumir a formação continuada a partir de práticas pedagógicas cotidianas de professores significará romper com visões clássicas institucionalizadas e instituídas, mas principalmente permitirá que saberes produzidos a partir de potencialidades cotidianas se formulem como pistas de reflexão epistemológica à modalidade da Educação de Jovens e Adultos. Como isto será feito, com quem, para quem e para quê, tem-se apresentado como desafio constante ao pensamento complexo.

As práticas pedagógicas docentes atravessadas por leituras de mundo diferenciadas constituem renovadas redes de saberesfazerespoderes que poderiam ser, no debate construtivo, compreendidas como complexidades possíveis de tradução à formação continuada da professora e, quiçá, de seus companheiros de trabalho na EJA. O conjunto de inacabamentos sentidos pela professora, ao se defrontar cotidianamente com a realidade, tendo que reinventá-la; as dúvidas e incertezas sobre o quê e o como fazê-lo; a ausência na maioria do tempo de apoio pedagógico; a vontade manifesta de evitar a evasão; a subversão ao "programa" instituído a priori e o enfrentamento de regulações impostas pelo imaginário social e acadêmico do ser professor traduzem, à visão do pensamento complexo, dispositivos inteligíveis à formação continuada docente ou, ainda na perspectiva da sociologia das emergências de Santos (2002), indícios emancipatórios que ajudam na reflexão e reconstrução do fazer docente cotidiano.

Do relato da professora, destaco, também, para enlaçar como indício emancipatório, o ato de replanejar e a relação de confiança construída com os estudantes, numa realidade em que a insegurança e as incertezas da nova profissão eram intensas. A coragem de rever, revisitar e redimensionar o pensado em detrimento do praticado, entendendo o vivido como gerador de recursividade significa, à compreensão que assumo neste trabalho, potencial de aprendizagem. Socorro Barbosa aprendeu com e pelas práticas pedagógicas cotidianas a ser professora formou-se continuadamente no efetivo exercício da prática. Desafiada pelo processo, não recuou; ao contrário, lançou-se às complexidades das práticas, articulando saberes, 
emancipando-se pelo risco, no deslizamento, provocando em si e no outro (seus alunos) acoplamentos não dedutíveis, (re)conhecidos, agora, por meio dos rastros de memória da experiência pedagógica vivida com jovens e adultos.

Os saberes práticos, rememorados pela professora são, pela lógica reducionista de conhecimento subalternizado, ausentes dos processos decisórios de formação continuada, e reforçam a premissa de que o que é produzido no senso comum não é saber válido; ainda, de que a prática é subordinada a um conjunto uniforme de teorias; e, por último, de que o professor é mero espectador de formações externas - consequentemente, transmissor de conteúdos e o aluno consumidor alienado desse saber.

Em síntese, percebo que existe uma inteligência do saber prático cotidiano sendo desperdiçada, que pode ser traduzida como saber legitimador em contextos de formação continuada. Essa compreensão exige esforço intelectual, vontade crítica, capacidade reflexiva e coragem epistemológica dos que praticam/pensam a formação continuada, e isso implica, como sugere Oliveira (2008), reconhecer e valorizar múltiplos currículos pensadospraticados e as práticas de solidariedade neles existentes, enquanto possibilidades de formação continuada.

\section{Considerações finais}

Desafiada pela concepção filosófica aprender por toda a vida - a formação continuada de professores da Educação de Jovens, Adultos e Idosos reconhece, potencializa, traduz e reconstrói práticas sociais, culturais e pedagógicas como movimentos impulsionadores de reflexão e de emancipação social nesta modalidade educativa e de ensino. Esses processos, pelo caráter democratizante que os constitui, permitem que professores e alunos sejam autores e reformuladores de práticas e de propostas pedagógicas vividas cotidianamente na escola.

Esses outros modos, denominados a partir da epistemologia do pensamento complexo, de formação em rede autopoiética tem como movimentos o reconhecimento, a potencialização, a tradução e a reconstrução de práticas pedagógicas cotidianas vivenciadas/tecidas pelos professores. A tradução desses movimentos em processos de formação continuada passa pela condição de que os professores vão assumindo uma identidade docente, o que supõe o reconhecimento do fato de se perceberem sujeitos da formação, e não objetos dela, como meros 
instrumentos maleáveis e manipuláveis. Não se devem confundir processos de formação continuada pensada por seus praticantespensantes com aquelas propostas que tentam dar respostas de forma igual a todos. Ao contrário, é preciso tomar cuidado com os modos imperialistas de tradução.

A formação de professores que contribua para a justiça social instala no centro do processo a diversidade de saberesfazerespoderes que alunos e professores dispõem e constroem diariamente, para além dos muros da escola, nas diferentes práticas sociais em que estão inseridos como pais, membros de associações, como lideranças, representantes políticos etc.

O propósito de se trabalhar com formação de professores para a justiça social, segundo Zeichner (2008), é fundamental em sociedades que lutam por sistemas democratizantes de vida e tentam superar práticas sociais hierarquizadas a que historicamente foram submetidos. A abordagem teórica apresenta alguns pressupostos possíveis de enredamento ao trabalho multirreferenciado, que estou cindindo com processos de formação continuada de professores da Educação de Jovens e Adultos, a partir de práticas pedagógicas cotidianas.

A formação continuada de professores, enquanto processo que ocorre em simbiose com os múltiplos espaços/tempos das práticas sociais cotidianas, encontra, na abordagem da formação de professores para a justiça social, campo fértil de possibilidades, problematizações, tensões e variações que, em larga escala, ajuda na compreensão e reconhecimento de práticas pedagógicas ausentes e emergentes.

É desafiador pensar processos formativos continuados de professores sob o prisma da justiça social, visto que um de seus objetivos é formar líderes da mudança social - questão em certa medida já em desenvolvimento em práticas pedagógicas cotidianas. Mas, os desafios postos, quando entrelaçados especificamente à formação de professores que trabalham com a modalidade de ensino EJA, se fortalecem, porque encontram nesses praticantes/pensantes e em suas realidades docentes, semelhantes necessidades de reconhecimento e reconstrução social.

\section{Referências}

ALVES, N. Decifrando o pergaminho - os cotidianos das escolas nas lógicas das redes cotidianas. In: OLIVEIRA, I. B.; ALVES, N. (orgs.). Pesquisas nos/dos/com os cotidianos das escolas: sobre redes de saberes. Petrópolis: DP et Alii, 2008. p.15-38 
CERTEAU, M. A invenção do cotidiano. Trad. Ephraim Ferreira Alves. 17.ed. Petrópolis, Rio de Janeiro: Vozes, 2011.

CHAVEAU, A. Questões para a história do presente. Trad. Ilka S. Cohen. Bauru, São Paulo: EDUSC, 1999.

FREIRE, P. Pedagogia do oprimido. 32.ed. Rio de Janeiro: Paz e Terra, 2002.

GUEDES-PINTO, A. L. Memórias de leitura e formação de professores. [Coleção Gêneros e Formação], Campinas, São Paulo: Mercado de Letras, 2008.

HALBWACHS, M. A memória coletiva. Trad. Beatriz Sidou. São Paulo: Centauro, 2006.

LE GOFF, J. História e memória. Trad. Bernardo Leitão. Campinas, São Paulo: Editora da Unicamp, 1990.

MACEDO, R. S. Outras luzes: um rigor intercrítico para uma etnopesquisa política. In. MACEDO, R. S.; GALEFFI, D.; PIMENTEL, A. (orgs.). Um rigor outro sobre a qualidade na pesquisa qualitativa: educação e ciências humanas. Salvador: EDUFBA, 2009. p.75-126

MORIN, E. Introdução ao pensamento complexo. Trad. Eliane Lisboa. 4.ed. Porto Alegre: Sulina, 2011.

OLIVEIRA, I. B. Criação curricular, autoformação e formação continuada no cotidiano escolar. In: FERRAÇO, C. E. (org.). Cotidiano escolar, formação de professores(as) e currículo. 2.ed. São Paulo: Cortez, 2008. p.43-67

OLIVEIRA, I. B.; SÜSSEKIND, M. L. (orgs.). Formação docente e justiça cognitiva: pesquisas, práticas e possibilidades. Rio de Janeiro: DP et Alii, 2016.

RICOEUR, Paul. A memória, a história, o esquecimento. Trad. Alain Fraçois [et al]. Campinas, São Paulo: Editora da Unicamp, 2007.

SANTOS, B. S. Para uma sociologia das ausências e uma sociologia das emergências. Revista Crítica de Ciências Sociais. n.63, p.237-280, out. 2002. Disponível em: www.boaventuradesousasantos.pt. Acesso em: 23 mar. 2014.

SANTOS, B. S. A crítica da razão indolente: contra o desperdício da experiência. 7.ed. São Paulo: Cortez, 2009.

SANTOS, B. S. Para além do pensamento abissal: das linhas globais a uma ecologia de saberes. In: SANTOS, B. S.; MENESES, M. P.(orgs.). Epistemologias do Sul. São Paulo: Cortez, 2010. p.3183

ZEICHENER, K. M. Formação de professores para a justiça social em tempos de incerteza e 
desigualdades crescentes. In: DINIZ-PEREIRA, J. E.; ZEICHENER, K. M. (orgs.). Justiça social: desafios para a formação de professores. Trad. Cristina Antunes, Belo Horizonte: Autêntica, 2008, p.11-34.

Recebido em fevereiro 2020.

Aprovado em setembro 2020. 